Ecological Applications, Vol. 11, No. 5, 2001, pp. 1425-1437.

(C) Ecological Society of America. All rights reserved.

http://www.esajournals.org/doi/pdf/10.1890/1051-0761(2001)011\%5B1425:VGSRWR\%5D2.0.CO\%3B2

http://www.esajournals.org/

doi: 10.1890/1051-0761(2001)011[1425:VGSRWR]2.0.CO;2

ISSN: 1051-0761

\title{
VARIABLE GIZZARD SHAD RECRUITMENT WITH RESERVOIR PRODUCTIVITY: CAUSES AND IMPLICATIONS FOR CLASSIFYING SYSTEMS
}

\author{
MARY T. B REMIGAN AND ROY A. STEIN \\ Aquatic Ecology Laboratory, Department of Evolution, Ecology, and Organismal Biology, The \\ Ohio State University.
}

\begin{abstract}
Achieving sustainable prey fish assemblages that support sport fish predator populations is a fundamental challenge to fisheries managers. Among Midwestern and Southeastern (USA) reservoirs, gizzard shad, Dorosoma cepedianum, have been widely stocked to improve predator growth. However, these stockings have yielded highly variable effects on sport fish, due in part to highly variable recruitment of gizzard shad. To determine whether reservoir productivity can be used to classify reservoirs according to recruitment of gizzard shad, we quantified gizzard shad recruitment along a mesotrophic to hypereutrophic productivity gradient. We sampled 12 reservoirs during May through June 1993, to evaluate the hypothesis that larval gizzard shad foraging success and survival increase with reservoir productivity. Both hatch abundance and survival of larval gizzard shad correlated positively with total phosphorus concentrations (TP), an indicator of reservoir productivity. Abundance of 15-mm (total length) larval gizzard shad survivors, an indicator of age- 0 year class strength, increased by two orders of magnitude across TP concentrations. Larval gizzard shad foraging success increased with availability of preferred, small zooplankton prey. However, abundance of small zooplankton did not increase with reservoir TP concentrations, and larval survival did not increase with foraging success. These results provide mechanistic understanding for the relative lack of gizzard shad in mesotrophic reservoirs, and the dominance of gizzard shad in hypereutrophic reservoirs. In hypereutrophic reservoirs, negative effects of gizzard shad on sport fish may be alleviated by reducing phosphorus loading from the watershed, suggesting a watershed approach to this fishery and water quality problem.
\end{abstract}

\section{INTRODUCTION}

Achieving sustainable prey fish assemblages that support sport fish predator populations remains a fundamental challenge to fisheries managers (Noble 1981, DeVries and Stein 1990). Consequently, predator-prey interactions in fish communities have a rich history of study in a wide variety of systems. For example, in small ponds, pioneering research related the relative abundances of predator and prey (i.e., "balance") to the sustainability of quality fishing (Swingle 1949). Currently in the Great Lakes, identification of salmonid stock levels that can be supported by fluctuating alewife populations has large economic implications (Jones et al. 1993).

Availability of prey fishes to their predators can determine predator consumption, growth, and survival (Hart and Connellan 1984, Storck 1986, Kerfoot and Sih 1987, Wahl and Stein 1988, Olson 1996, Ludsin and DeVries 1997). However, effects of prey fish availability on predators can be complicated by a variety of food web interactions. First, prey may be competitors both with earlier life stages of the predator and with alternative prey of the predator (Werner and Gilliam 1984, Olson et al. 1995). Second, variability in prey fish recruitment can be large both among systems and among years within a system. Unfortunately, this variability makes prediction of prey fish effects on predators very difficult, and can severely limit a manager's ability to manage multiple systems over multiple years.

One way to improve our understanding of these complex predator-prey relationships is to 
identify the processes that determine prey fish recruitment. This understanding will allow more effective management, particularly when the predator's primary prey are age- 0 fishes. Interannual variability in prey fish recruitment, and its effects on predator population abundance and consumptive demand, has been demonstrated by detailed measurements (Mills and Forney 1988). However, intersystem variability in prey fish recruitment has received little investigation. Identifying predictable intersystem patterns of prey fish recruitment could greatly aid managers in their quest for improving piscivore fishery yield. These patterns would allow managers to classify systems into groups that can be managed similarly, given similar prey populations, and presumably, similar effects of prey fish on predator growth.

We seek to determine whether recruitment of gizzard shad, Dorosoma cepedianum, varies predictably across a productivity gradient in midwestern U.S. reservoirs. Gizzard shad are zooplanktivorous as larvae (age- $0<25 \mathrm{~mm}$ total length [TL]) and omnivorous in post-larval stages (Bodola 1966, Noble 1981, Drenner et al. 1986, Mundahl and Wissing 1987, Dettmers and Stein 1992). Within midwestern and southeastern U.S. reservoirs, prey fish communities are typically dominated by gizzard shad or threadfin shad (D. petenense; Noble 1981, DeVries and Stein 1990). Widespread stocking of both gizzard shad and threadfin shad to enhance predator growth rates has yielded highly variable results, with evidence for positive, negative, and no effects of shad on predator growth (DeVries and Stein 1990). In particular, age-0 gizzard shad can positively affect growth of age-0 largemouth bass, Micropterus salmoides, when gizzard shad remain vulnerable to this predator throughout its first summer (Storck 1986, Adams and DeAngelis 1987, Garvey and Stein 1998). Conversely, age-0 gizzard shad can negatively affect recruitment of bluegill, Lepomis macrochirus, an alternative prey of age-0 largemouth bass (Stein et al. 1995, 1996). When consumption of zooplankton by post-larval gizzard shad causes severe midsummer zooplankton declines (Dettmers and Stein 1992, DeVries and Stein 1992), exploitative competition with and poor recruitment of zooplanktivorous larval bluegill result (DeVries et al. 1991). In turn, fewer age-0 bluegill leads to slower growth of their age-0 largemouth bass predators (DeVries et al. 1991, Stein et al. 1995, Garvey et al. 1998). We seek to improve our ability to predict these variable effects of age- 0 gizzard shad on age- 0 sport fish by considering recruitment processes along the gradient of reservoir productivity.

Although we know that gizzard shad population abundance increases with reservoir productivity (Bachman et al. 1996, DiCenzo et al. 1996), the extent to which gizzard shad recruitment varies with productivity has not been established. We are interested in determining whether reservoir productivity can be used to classify reservoirs according to their potential for age-0 gizzard shad effects on age-0 sport fish. Further, the mechanisms driving gizzard shad recruitment have not been identified. We seek to identify the relative importance of factors influencing hatch and survival to determine whether gizzard shad recruitment can be predicted and perhaps manipulated by reservoir managers.

In this manuscript, we extend our experimentally evaluated hypothesis, linking availability of small zooplankton prey to larval gizzard shad foraging and survival (Bremigan and Stein 1994, 1997), to the scale of whole reservoirs. We examine the relationships among nutrients, chlorophyll $a$, zooplankton, and larval gizzard shad hatching abundance, foraging success and survival across a productivity gradient in 12 reservoirs ranging from mesotrophic to hypereutrophic. We hypothesize that nutrient levels (total phosphorus [TP]) are positively correlated with both chlorophyll $a$ and small zooplankton abundance during May through June when larval gizzard shad recruit. We reason that hatch abundance of larval gizzard shad should not limit recruitment because adult gizzard shad are extremely fecund (Bodola 1966, Parrish and Vondracek 1989, Miranda et al. 1994). Rather, we expect larval survival to determine gizzard shad recruitment, reflecting positive effects of small zooplankton on larval gizzard shad foraging 
success and survival, which will increase with increasing reservoir productivity. Thus, with increasing reservoir productivity, gizzard shad should establish increasingly stronger year classes, due primarily to the recruitment environment that they experience as larvae.

\section{METHODS}

Reservoir productivity and larval gizzard shad density

We sampled larval gizzard shad in 12 reservoirs of differing productivities (Table 1). Smallest reservoirs were hypereutrophic, whereas larger reservoirs were mesotrophic to hypereutrophic (based on TP and chlorophyll $a$ values, see Results). Reservoirs were sampled weekly during May through June to evaluate relationships among larval gizzard shad abundance, foraging, and survival, zooplankton assemblages, chlorophyll $a$ concentration, and nutrient levels. A subset of reservoirs was also sampled weekly during July and August, primarily to evaluate whether larval gizzard shad hatching was concentrated in May and June.

\section{Larval gizzard shad}

Larval gizzard shad were collected offshore using two replicate surface tows of a $0.75-\mathrm{m}$ diameter ichthyoplankton net $(500-\mu \mathrm{m}$ mesh) towed for $5 \mathrm{~min}$ at $1-1.5 \mathrm{~m} / \mathrm{s}$. Larvae were preserved in $95 \%$ ethanol. A flow meter mounted in the mouth of the net provided estimates of the water volume filtered to estimate larval gizzard shad density.

Larval gizzard shad were counted in each ichthyoplankton sample to estimate their density. We measured total length (nearest $0.1 \mathrm{~mm}$ ) of 50 larval gizzard shad from one randomly chosen replicate per date. On four dates, we analyzed larval gizzard shad diets by counting and identifying prey from the entire digestive tract of up to five larvae from each of two size classes (5-9.9 and 10-14.9 mm TL). We identified cladocerans to genus, copepod adults and copepodids as calanoid or cyclopoid, and immature copepods as nauplii. Rotifers were counted and treated as one taxonomic group. We assumed that number of prey items per larval gut reflected foraging success.

TABLE 1. Comparison of abiotic characteristics of 12 Ohio reservoirs sampled in 1993. Identification number (ID) ranks reservoirs from shallow to deep Secchi depth.

\begin{tabular}{rlrrrrrrr}
\hline \hline & & $\begin{array}{c}\text { Sam- } \\
\text { pling } \\
\text { regime }\end{array}$ & $\begin{array}{c}\text { Area } \\
(\text { ha) }\end{array}$ & Turnover & $\begin{array}{c}\text { Mean } \\
\text { depth } \\
\text { ID }\end{array}$ & $\begin{array}{c}\text { Maxi- } \\
\text { mum } \\
\text { depth } \\
(\mathrm{m})\end{array}$ & $\begin{array}{c}\text { Water- } \\
\text { shed } \\
\left(\mathrm{km}^{2}\right)\end{array}$ & $\begin{array}{c}\text { Secchi } \\
(\mathrm{m})\end{array}$ \\
\hline 1 & Llark & $\mathrm{A}$ & 41 & 10.6 & 1.4 & 2.7 & 18 & 0.4 \\
2 & Delaware & $\mathrm{B}$ & 526 & 16.0 & 3.3 & 9.4 & 987 & 0.5 \\
3 & Kokosing & $\mathrm{A}$ & 62 & 11.4 & 2.0 & 4.9 & 114 & 0.5 \\
4 & Stonelick & $\mathrm{A}$ & 69 & 10.8 & 3.1 & 6.4 & 60 & 0.5 \\
5 & Norwalk & $\mathrm{B}$ & 11 & $\mathrm{NA}$ & $\mathrm{NA}$ & $\mathrm{NA}$ & $\mathrm{NA}$ & 0.7 \\
6 & Logan & $\mathrm{A}$ & 138 & 3.4 & 2.8 & 7.3 & 36 & 0.9 \\
7 & Pleasant Hill & $\mathrm{A}$ & 344 & 9.4 & 4.8 & 11.0 & 510 & 1.0 \\
8 & Tappan & $\mathrm{B}$ & 951 & 1.5 & 4.5 & 8.5 & 184 & 1.1 \\
9 & Caesar & $\mathrm{B}$ & 1145 & 1.7 & 11.0 & 30.5 & 614 & 1.2 \\
10 & Piedmont & $\mathrm{B}$ & 935 & 2 & 4.5 & 9.8 & $\mathrm{NA}$ & 1.2 \\
11 & CJ Brown & $\mathrm{A}$ & 858 & 1.3 & 5.3 & 12.2 & 212 & 1.2 \\
12 & Burr Oak & $\mathrm{A}$ & 269 & 2.6 & 4.3 & 10.7 & 85 & 1.4 \\
\hline
\end{tabular}

Notes: We quantified larval gizzard shad, zooplankton, and Secchi depth in all reservoirs during May through June. In "A" (sampling regime) reservoirs, we also determined chlorophyll $a$ and nutrient (total nitrogen and total phosphorus) levels, and we continued to sample larval gizzard shad through August; in "B" reservoirs, we measured Secchi depth, but not chlorophyll $a$ or nutrient levels, and we collected zooplankton and larval gizzard shad during May through June. Reservoir 5 was an upground reservoir; all others were onstream impoundments. Turnover was calculated as inflow (cubic meters per year) divided by capacity (cubic meters). NA = not available. 
On each date, we calculated mean larval gizzard shad density across the two replicate tows. We generated indices of larval gizzard shad hatch abundance and large larval gizzard shad survivor abundance by combining density and length data. The index of larval gizzard shad hatch was calculated as the cumulative abundance (May through June) of 5-6 mm TL larvae. The index of large larval gizzard shad survivors was calculated as the cumulative abundance of larvae that reached $\sim 15 \mathrm{~mm}$ TL.

We attempted to account for the potential for larval growth rate differences across reservoirs to influence index estimates. Slow-growing larvae will remain in a particular size class longer than will fast-growing larvae. As a result, a slow-growing population of larvae could yield a higher estimate of cumulative density over time than would a fast-growing one, even if the actual densities were similar. We identified minimum and maximum growth rates $(0.66$ and 0.94 $\mathrm{mm} / \mathrm{d}$, respectively) for larval gizzard shad $<15 \mathrm{~mm}$ TL based on otolith analysis of 9-15 mm TL larval gizzard shad (Bremigan and Stein 1999). Minimum and maximum growth rates were not reservoir specific. Using these extreme growth rates, we generated minimum and maximum hatch abundance and large larval survivor abundance estimates for each reservoir.

We used the abundance of 5-6 mm TL larvae as our estimate of the hatch index because 5 $\mathrm{mm}$ is the smallest size that are fully vulnerable to our nets, and using larger sizes would introduce the effects of mortality from hatching at $3.5 \mathrm{~mm}$ TL (Carlander 1969) to the larger size. To calculate our index of cumulative hatch abundance, we estimated the abundance of 5-6 mm TL larvae produced each week based on our weekly point-in-time estimates. We accounted for the fact that larvae could grow into and out of the 5-6 mm TL interval between weekly sampling dates, by using the equation:

$$
\begin{aligned}
& \frac{\text { No. of time intervals for } 1 \mathrm{~mm} \text { growth }}{\text { week }} \times \frac{\text { No. of larvae }}{\mathrm{m}^{3}} \\
& =\frac{\text { No. of larvae }}{\mathrm{m}^{3} \times \text { week }}
\end{aligned}
$$

where

$$
\begin{aligned}
& \text { No. of time intervals for } 1 \mathrm{~mm} \text { growth } \\
& \quad=\frac{7 \text { days }}{\text { week }} \times \frac{1}{\text { No. of days to grow } 1 \mathrm{~mm}}
\end{aligned}
$$

and number of days to grow $1 \mathrm{~mm}=1.52 \mathrm{~d}$ and $1.06 \mathrm{~d}$, based on minimum and maximum growth rate scenarios, respectively. We summed these weekly hatch abundance estimates to generate minimum and maximum index estimates for May through June hatch abundance in each reservoir.

We used abundance of $15 \mathrm{~mm}$ TL fish for our index of large larval survivor abundance because preliminary analysis indicated that the majority of larval mortality occurred for individuals $<11 \mathrm{~mm} \mathrm{TL}$, and because vulnerability to our ichthyoplankton net declines for larvae $>15 \mathrm{~mm}$ TL. We calculated the production of $15 \mathrm{~mm}$ TL survivors each week, based on weekly point-in-time estimates. Based on the absolute amount that a larval fish grows during $1 \mathrm{wk}$ (4.5 $\mathrm{mm}$ and $6.5 \mathrm{~mm}$ for minimum and maximum growth rate scenarios, respectively), we calculated 
weekly growth increments (10.5-15 mm TL and 8.5-15 mm TL for minimum and maximum growth rate scenarios, respectively). For any weekly point-in-time estimate, all larvae within the weekly growth increment would grow to $15 \mathrm{~mm}$ TL prior to the next sampling date. We calculated the density of larvae in the weekly growth increments on each sampling date, and then summed the weekly densities to estimate the cumulative May through June abundance of large larval survivors. These calculations assumed that all larvae in the weekly growth increment survive to $15 \mathrm{~mm}$. This approach provides a conservative estimate of differences in large larval survivor abundance across reservoirs because it overestimates abundance of survivors produced in reservoirs with relatively high mortality rates of individuals within the weekly growth increment. Therefore, differences among reservoirs in the number of large larval survivors produced are likely greater than those calculated.

We calculated larval survival as a range of values. The endpoints of each range were generated by dividing the cumulative survivor abundance by cumulative hatch abundance, first with both values based on minimum growth rates, and next with both values based on maximum growth rates.

\section{Zooplankton}

Zooplankton were sampled at 2-3 sites per reservoir near the areas sampled for larval gizzard shad. In 11 of 12 reservoirs, zooplankton were collected using vertical net hauls from bottom to surface with a simple cone net, $98 \mathrm{~cm}$ long $\times 35 \mathrm{~cm}$ diameter $(54-\mu \mathrm{m} \mathrm{mesh})$. In Reservoir 1 (Clark), which was relatively shallow, we collected zooplankton with a $7.3 \mathrm{~cm}$ diameter tube sampler using four 1-m hauls or two 2-m hauls (depending on site depth). Once collected, all zooplankton retained by a $54-\mu \mathrm{m}$ mesh were preserved in $70 \%$ ethanol.

To quantify crustacean zooplankton, we identified, counted, and measured crustacean zooplankton using a digitizing tablet viewed through a dissecting microscope drawing tube. Zooplankton were identified to taxa as follows: cladocerans to genus; copepod adults and copepodids as calanoid or cyclopoid; immature copepods as nauplii. Each zooplankton sample was placed in a dish divided into 16 equal-sized wedges. All individuals were counted from two opposite wedges of the dish. From these counts, the total number of individuals within each taxon in the entire sample was estimated. If this number was $\geq 25$, then counting of complete wedges continued until at least 50 individuals of that taxon were counted and the total body length (excluding spines, helmets, and caudal rami) of the first 22 individuals encountered was measured. If the total number of individuals of a taxon, as estimated from the first two wedges, was $<25$, then counting of that taxon stopped because it contributed so little to the entire sample, and the original estimate of abundance was retained. We assumed the zooplankton net was 100\% efficient, and converted zooplankton densities from Reservoir 1 (Clark), sampled with a tube sampler, to equivalent net densities using the conversions of DeVries and Stein (1991). We calculated crustacean zooplankton biomass using taxon-specific length-dry mass regressions (Dumont et al. 1975, Bottrell et al. 1976; G. G. Mittelbach, Kellogg Biological Station, Michigan State University, unpublished data).

To calculate crustacean zooplankton production rates (Culver and DeMott 1978), we quantified, for each sample, the percentage of females in each taxon bearing eggs, and the mean number of eggs per egg-bearing female. We then summed the rate of increase in mass of existing individuals (growth in $\mathrm{mg}$ dry mass $\cdot \mathrm{L}^{-1} \cdot \mathrm{d}^{-1}$ ) and the rate at which zooplankton mass was generated through births of new individuals (reproduction in $\mathrm{mg}$ dry mass $\cdot \mathrm{L}^{-1} \cdot \mathrm{d}^{-1}$ ). We used taxon- and temperature-dependent zooplankton development rates (DeMott 1976, Bean 1980). The sum of the growth and reproduction estimates yielded taxon-specific production estimates. We summed these estimates across taxa to calculate total crustacean zooplankton production per 
sample. For each zooplankton parameter (density, size, biomass, and production), we first calculated daily means by averaging across sites; we then generated an overall mean by averaging across dates during May through June.

\section{Chlorophyll a, nutrients, water clarity, and temperature}

At each zooplankton collection site, we measured Secchi depth. At the most downstream site in each reservoir, we measured surface water temperature. In 7 of 12 reservoirs (Table 1), we collected a water sample from the euphotic zone (calculated as 1.5 times the Secchi depth), using an integrated tube sampler $(2.5 \mathrm{~cm}$ diameter), for laboratory determination of chlorophyll $a$, total nitrogen (TN), and TP. Total N and TP samples were collected about once every two weeks. Water samples were transported to the laboratory in a cooler on ice.

To measure the concentration of chlorophyll $a$ from phytoplankton edible to zooplankton, we filtered the water samples (typically $50 \mathrm{~mL}$ ) in a darkened room through $35-\mu \mathrm{m}$ mesh (Gliwicz 1975, Porter 1977). The samples were then filtered onto Whatman GF/C glass fiber filters and frozen. Chlorophyll $a$ concentrations (corrected for pheopigments) were determined fluorometrically, after extraction in methanol (Soranno 1990).

Total N and TP concentration samples were frozen in Nalgene bottles immediately upon return to the laboratory. Total $\mathrm{N}$ was determined by second-derivative spectroscopy after persulfate digestion (Crampton et al. 1992), and TP was determined by spectroscopic analysis using the acid molybdate method after persulfate digestion.

TABLE 2. Response variable, explanatory variable, and predicted relationship for simple linear regression analysis.

\begin{tabular}{llc}
\hline \hline \multicolumn{1}{c}{ Response variable } & \multicolumn{1}{c}{$\begin{array}{c}\text { Predicted } \\
\text { relationship }\end{array}$} \\
\hline Mean May-June TP & mean May-June Secchi depth & negative \\
Total May-June larval hatch abundance & mean May-June TP & none \\
Total May-June abundance of large larval survivors & mean May-June TP & positive \\
parval survival & mean May-June TP & positive \\
Mean May-June edible chlorophyll a & mean May-June TP & positive \\
Mean May-June crustacean zooplankton production & mean May-June TP & pegative \\
Mean May-June crustacean zooplankton length & mean May-June TP & positive \\
Mean May-June density of small copepods & mean May-June TP & positive \\
Mean number of copepods per larval gut & mean May-June density of small copepods & larval foraging success \\
Larval survival & &
\end{tabular}

Notes: Analyses first evaluated how aspects of gizzard shad recruitment (hatch, survivor abundance, survival) varied with reservoir productivity. Subsequent analyses sought mechanistic insights underlying the documented recruitment patterns. $\mathrm{TP}=$ total phosphorus.

We calculated daily means of edible chlorophyll $a$ by averaging across sites. Next, we generated an overall mean value for edible chlorophyll $a$ in each reservoir by averaging across dates during May through June. Mean May through June values of TN, TP, and Secchi depth were calculated by averaging across sample dates.

\section{Statistical analyses}

We used linear regression to evaluate relationships between gizzard shad-related variables and measures of reservoir productivity (Table 2). The majority of our regressions consisted of single observations per reservoir $(N=12)$ because we generated single estimates of larval hatch abundance, larval survival, and production of large larval survivors in each reservoir. Unless otherwise noted, data transformations were not needed. 
We also compared larval gizzard shad foraging success to zooplankton availability at a finer, weekly time scale to determine if larval foraging success increased with availability of small crustacean zooplankton prey (Bremigan and Stein 1994, 1997). We estimated the density of preferred, small crustacean zooplankton prey (small copepods and nauplii $<0.40 \mathrm{~mm}$ ) in each reservoir on each sampling date. We combined larvae from dates with similar reservoir densities of small copepods. Overall, 488 larvae were grouped into five categories of small copepod density: $<10 / \mathrm{L}, 10$ to $<20 / \mathrm{L}, 20$ to $<40 / \mathrm{L}, 40$ to $<60 / \mathrm{L}$, and $\geq 60 / \mathrm{L}$. We compared the mean number of small copepods per larval gut among the five small copepod density categories using analysis of variance, followed by Tukey's pairwise comparisons.

\section{RESULTS}

Reservoir productivity and larval gizzard shad density

Across seven reservoirs, mean TP ranged from $28-328(\mu \mathrm{g} / \mathrm{L}$ and mean TN ranged from $8990-9981 \mu \mathrm{g} / \mathrm{L}$. Total N:TP ratios ranged from 25 to 400 by mass, always exceeding the Redfield ratio (7:1 ratio by mass; Lind 1985), indicating that phytoplankton in these reservoirs likely were phosphorus limited. Therefore, we used mean TP as a measure of reservoir productivity. Because mean Secchi depth and mean TP were significantly correlated, we estimated TP in the five reservoirs in which only Secchi depth was measured using the SecchiTP regression equation (Fig. 1).

Hatching of larval gizzard shad began the second week of May, and continued through June, except in Reservoir 4 (Stonelick), where hatching was delayed. By June 15, typically $>70 \%$ of the May through June hatching had occurred, although in Reservoir 4 only $40 \%$ had occurred. In five of the seven reservoirs $(3,6,7,11,12)$ that we sampled through the summer, few larval gizzard shad hatched (i.e., $<0.1$ larvae $/ \mathrm{m}^{3}$ ) after 30 June. However, in two small, hypereutrophic reservoirs $(1,4)$ up to 15 larvae $/ \mathrm{m}^{3}$ hatched after June 30 .

Overall, hatch abundance, abundance of large larval gizzard shad survivors, and larval gizzard shad survival all varied more extensively among reservoirs than did the within-reservoir estimates based on minimum and maximum growth rate scenarios, and all three variables were positively correlated with TP (Fig. 2). In contrast to our prediction that larval gizzard shad hatch abundance would be consistently high, regardless of reservoir productivity, mean cumulative larval hatch increased from 2 to 77 larvae $/ \mathrm{m}^{3}$ with increasing mean TP (Fig. 2A). Both hatch abundance and survival contributed to increasing abundance of large larval survivors with increasing productivity (Fig. 2B, C).

\section{Larval recruitment environments: nutrient, chlorophyll a, and zooplankton relationships}

As we expected, mean edible chlorophyll $a$, which ranged from $5-100(\mu \mathrm{g} / \mathrm{L}$, was positively correlated with mean TP (Fig. 3A). Contrary to our expectations, crustacean zooplankton production, which ranged from $0.01-0.08 \mathrm{mg}$ dry mass $\cdot \mathrm{L}^{-1} 1 \mathrm{~d}^{-1}$ across reservoirs, was not correlated to mean TP (Fig. 3B).

Taxonomic composition of crustacean zooplankton assemblages varied across reservoirs. Typically, copepods were most prevalent. Across reservoirs, mean proportion of crustacean zooplankton biomass comprised of copepods ranged from $2-60 \%$ for calanoid copepods and from $4-52 \%$ for cyclopoid copepods. 


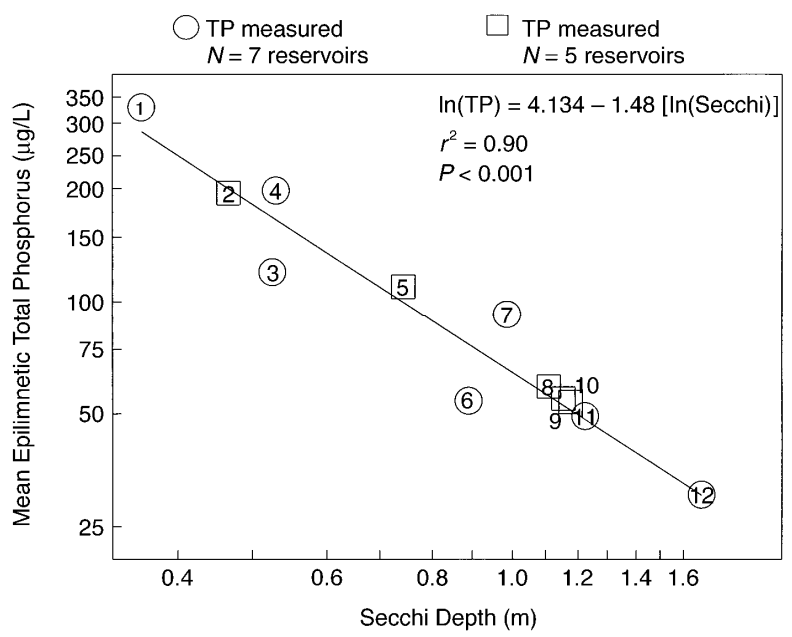

FIG. 1. Relationship between mean total epilimnetic phosphorus concentration (TP) and Secchi depth in Ohio reservoirs, sampled during May through June 1993. Secchi depth was measured weekly in all 12 reservoirs, whereas TP was measured in seven reservoirs (open circles) once every two weeks. Regression analysis on natural-logtransformed data from the seven reservoirs allowed estimation of TP in the five reservoirs in which only Secchi depth was measured (open squares). Reservoirs were ranked from shallowest (1) to deepest (12) Secchi depth (see Table 1).

Copepod nauplii also contributed from $2-19 \%$ of crustacean zooplankton biomass. The proportion of zooplankton biomass attributable to cladocerans ranged widely $(<1-15 \%$ for Bosmina spp., 10-74\% for Daphnia spp., and $<1-14 \%$ for Diaphanosoma spp.). Mean crustacean zooplankton length ranged $0.46-0.70 \mathrm{~mm}$ across reservoirs, but was unrelated to TP $\left(r^{2}=0.16, P\right.$ $=0.22, N=12$ reservoirs).

\section{Larval gizzard shad foraging on zooplankton}

Larval gizzard shad primarily consumed copepod nauplii and copepods $<0.40 \mathrm{~mm}$ (hereafter, small copepods). For small larvae (5-9.9 mm TL), 70\% of all prey items were small copepods. For large larvae (10-14.9 mm TL), 79\% of all prey items were small copepods. Larvae occasionally consumed rotifers (29\% and $16 \%$ of all prey in small and large larvae, respectively). Small cladocerans, which typically are preferred by larvae $>15 \mathrm{~mm}$ TL (Dettmers and Stein 1992, Bremigan and Stein 1994), were quite rare in the small and large larval guts sampled here ( $<5 \%$ in both size classes). Many larval gizzard shad contained no prey (percentage empty: small larvae $=57 \%$, large larvae $=36 \%$ )

Mean May through June density of small copepods was unrelated to mean TP (Fig. 3C). For small larvae, mean May through June density of small copepods per larval gut increased with reservoir mean density of small copepods (Fig. 4A); rotifers were only abundant in larval guts in reservoirs where small copepods were rare (Fig. 4B). For large larvae, small copepods in the diet were not related to reservoir density of small copepods (Fig. 4C); rotifers per large larval gut were generally low (Fig. 4D). The number of small copepods per larval gut did not explain larval survival for either small or large larvae $(P>0.5$ for both larval size classes).

A stronger relationship between larval foraging success and small copepod density was evident for both small and large larvae, when viewed at a weekly time scale (Fig. 5). For $<20$ small copepods/L, the percentage of larvae with empty guts was quite high $(62 \%$ and $50 \%$ for small and large larvae, respectively), whereas for $\geq 60$ small copepods/L, fewer larvae had empty guts (35\% and $16 \%$ for small and large larvae, respectively). Overall, large larvae consumed 
more small copepods than small larvae; for both size classes, number of small copepods consumed increased with reservoir density of small copepods (Fig. 5).

\section{Discussion}

Our research explores how the mechanisms driving community structure and function in reservoirs vary along a productivity gradient. This pattern hinges on the success of a particular species, gizzard shad (Stein et al. 1995). We sought to explain among-system patterns of gizzard shad abundance by improving our mechanistic understanding of gizzard shad recruitment along a productivity gradient. By mechanistically understanding recruitment of this strong interactor (sensu Paine 1980), we gain insight into the variability surrounding community structure and nutrient dynamics in reservoirs. Such understanding is useful to the development of broadscale, multisystem management strategies. Below, we discuss our results in the context of factors affecting gizzard shad recruitment across reservoirs, and use of these results to improve reservoir management.

\section{Relative importance of hatch abundance and survival}

We explored if and when hatch abundance of larval gizzard shad limited recruitment in a subset of reservoirs that spanned the full range of TP $(1,4,8$, and 12). We estimated the number of larval survivors that could be produced if reservoirs with low larval gizzard shad hatch abundance (8 and 12) had supported high survival (values from 1 and 4) and vice versa (Table 3 ). Given all else being equal, abundant large larval survivors neither could be produced in low productivity/low hatch reservoirs, even if survival were high, nor in high productivity/high survival reservoirs, if hatch abundance were low. Hatch abundance likely limited recruitment in mesotrophic reservoirs ( $\leq 7 \mu \mathrm{g} / \mathrm{L}$ chlorophyll $a$; trophic classification per Bachman et al. [1996]). In contrast, among eutrophic $(8-40(\mu \mathrm{g} / \mathrm{L}$ chlorophyll $a)$ and hypereutrophic $(>40(\mu \mathrm{g} / \mathrm{L}$ chlorophyll $a$ ) reservoirs that supported moderate to high hatch abundance, survival determined recruitment. Thus, high hatch abundance appears necessary, but not sufficient, to produce abundant large larval gizzard shad survivors. Our data suggest that as reservoir productivity increases, hatch abundance increases, and correspondingly the potential for variability in the number of large larval survivors increases. However, if hypereutrophic reservoirs consistently support the highest hatches and survival (as documented here), then we expect consistently high recruitment in hypereutrophic reservoirs, consistently low recruitment in mesotrophic reservoirs, and variable recruitment in eutrophic reservoirs. We surmise that the factors underlying the positive relationship between hatch abundance and reservoir productivity reflect increasing adult abundance and/or condition. 


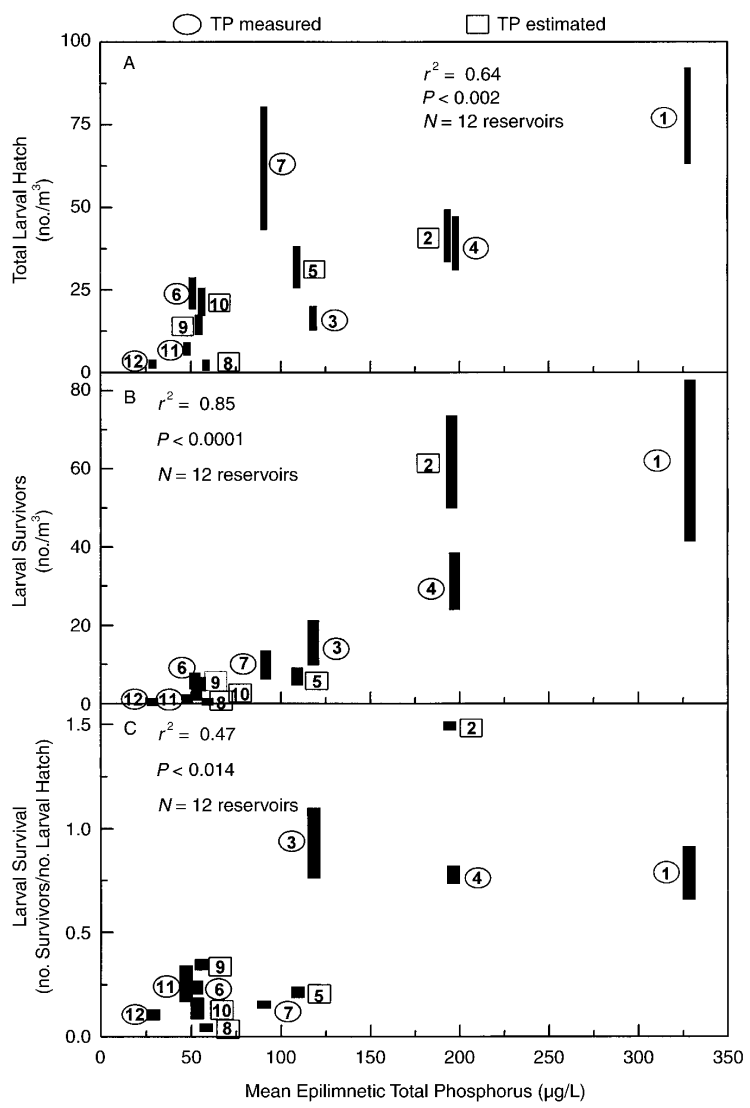

FIG. 2. (A) Positive relationship between the index of larval gizzard shad hatch abundance (total density of 5-6 mm TL larvae produced during May through June) and mean total epilimnetic phosphorus concentration in 12 Ohio reservoirs, 1993. (B) Positive relationship between cumulative abundance (May through June) of large larval gizzard shad survivors (larvae reaching $\sim 15 \mathrm{~mm} \mathrm{TL}$ ) and mean epilimnetic total phosphorus concentration in 12 Ohio reservoirs, sampled during May through June 1993. (C) Positive relationship between larval gizzard shad survival and mean epilimnetic total phosphorus concentration in 12 Ohio reservoirs. Survival represents the ratio of cumulative abundance of larval survivors (larvae reaching $\sim 15 \mathrm{~mm}$ TL) to cumulative hatch of larval gizzard shad. Reservoirs are ranked from shallowest (1) to deepest (12) Secchi depth (Table 1). For each response parameter (larval hatch abundance, survivor abundance, and survival), we estimated the range within which the actual value falls, accounting for the potential for larval growth rate differences across reservoirs to influence density estimates. Endpoints of each range were generated using minimum and maximum larval gizzard shad growth rates (see Methods: Larval gizzard shad for explanation). We used mean value for each response parameter (larval hatch abundance, survivor abundance, and survival; calculated as the average of the values generated from minimum and maximum growth rates) in the regression analysis. 


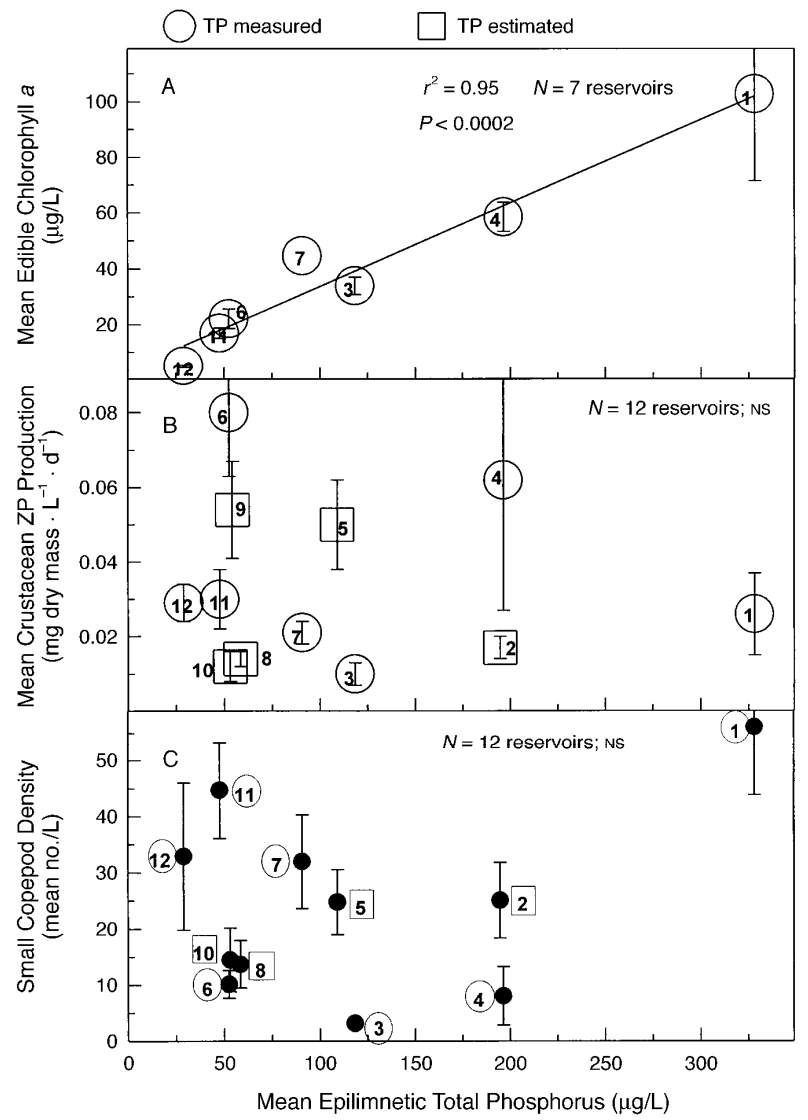

FIG. 3. (A) Positive relationship between mean epilimnetic edible chlorophyll $a$ concentration and mean epilimnetic total phosphorus concentration in seven Ohio reservoirs, 1993. Chlorophyll $a$ was measured weekly during May through June, except in reservoir 7, for which chlorophyll $a$ was sampled on only one date. Reservoirs were ranked from shallowest (1) to deepest (12) Secchi depth (see Table 1). (B) Comparison of mean crustacean zooplankton production and mean epilimnetic total phosphorus concentration in 12 Ohio reservoirs, 1993. Zooplankton were sampled weekly during May through June, 1993. (C) Comparison of mean density of small copepods (nauplii and individuals $<0.40 \mathrm{~mm}$ ) and mean epilimnetic total phosphorus in 12 Ohio reservoirs, sampled weekly during May through June 1993. Error bars represent $\pm 1 \mathrm{SE}$; NS = nonsignificant.

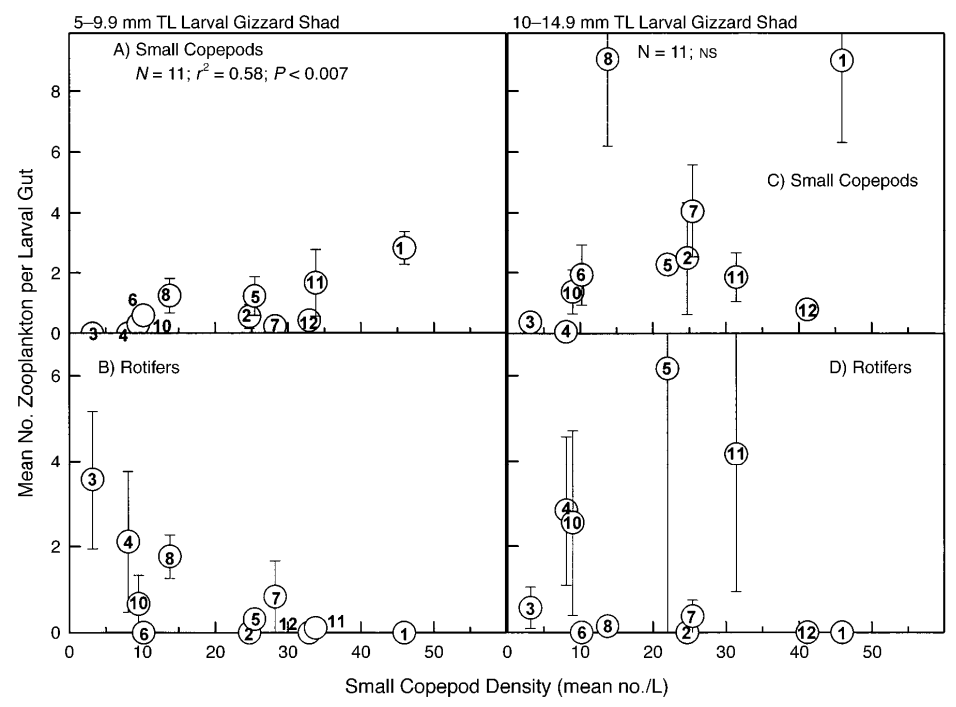


FIG. 4. Prevalence of zooplankton in larval guts and mean reservoir density of small copepods (nauplii and individuals $<0.40 \mathrm{~mm}$ ) for 11 reservoirs sampled during May through June 1993. Mean reservoir density of small copepods was estimated for dates on which larval guts were analyzed. Reservoirs were ranked from shallowest (1) to deepest (12) Secchi depth (Table 1). (A) Significant positive correlation between mean number of small copepods per small larval gizzard shad gut vs. mean reservoir density of small copepods. (B) Mean number of rotifers per small larval gizzard shad gut vs. mean reservoir density of small copepods. (C) Nonsignificant relationship between mean number of small copepods per large larval gizzard shad gut and mean reservoir density of small copepods. (D) Mean number of rotifers per large larval gizzard shad gut vs. mean reservoir density of small copepods. Error bars represent $\pm 1 \mathrm{SE}$; NS = nonsignificant.

We predicted that larval survival would increase with reservoir productivity, due to increasing availability of small zooplankton. As predicted, larval gizzard shad survival increased with reservoir TP, and larval foraging success increased with small zooplankton abundance. However, the extent to which these patterns reflected positive effects of small crustacean zooplankton on larval gizzard shad survival was difficult to discern because (1) small crustacean zooplankton productivity did not increase with reservoir productivity and (2) larval survival did not increase with larval foraging success. We consider these relationships in turn.

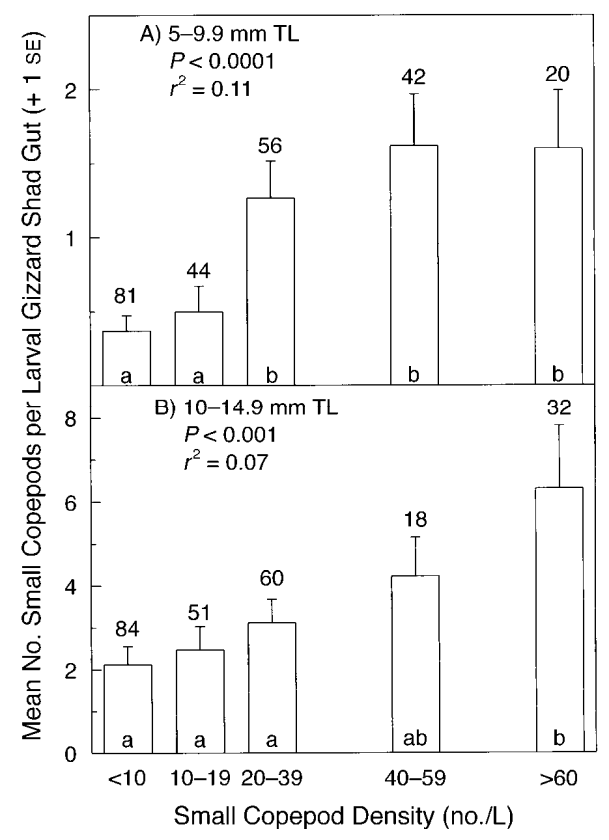

FIG. 5. Relationship between mean number of small copepods (nauplii and individuals $<0.40 \mathrm{~mm}$ ) per larval gizzard shad gut and reservoir density of small copepods for (A) small and (B) large larvae sampled during May through June 1993. Larvae were grouped according to reservoir density of small copepods. Letters signify significant differences (Tukey's pairwise comparisons, $\mathrm{a}=0.05$ ) among pairwise comparisons. The number of larval guts analyzed is shown above each bar.

\section{Zooplankton and system productivity}

We expected zooplankton production to increase and zooplankton size to decline with increasing reservoir TP and turbidity because high turbidity can negatively affect large zooplankton (Arruda et al. 1983). However, multisystem surveys of zooplankton size vs. lake or reservoir productivity have shown equivocal results (Table 4). In Ontario lakes (Sprules 1980) 
and Florida lakes (Bays and Crisman 1983) zooplankton size declined with increasing productivity. Yet, across a relatively narrow productivity range in Quebec lakes (Pace 1986), and a much wider productivity range in midwestern reservoirs (Canfield 1988), zooplankton size did not change with productivity. Although we detected no change in crustacean zooplankton size with increasing productivity, mean crustacean zooplankton size was consistently small (0.46 to $0.70 \mathrm{~mm})$ relative to north temperate lakes $(>0.70 \mathrm{~mm}$ in 22 of $36 \mathrm{New}$ York lakes; Mills et al. 1987). Further, Daphnia spp., often the dominant zooplankton grazer in north temperate lakes, was only abundant (i.e., $>60 \%$ of crustacean zooplankton biomass) in our two reservoirs with edible chlorophyll $a<20 \mu \mathrm{g} / \mathrm{L}$. Taken together, these patterns suggest that a reduction in zooplankton size with increasing productivity, if observed, occurs most markedly at $\sim 20 \mu \mathrm{g} / \mathrm{L}$ chlorophyll $a$, due to rarity of large Daphnia spp. and/or predominance of microzooplankton in systems with $>20 \mu \mathrm{g} / \mathrm{L}$ chlorophyll $a$.

In contrast to other multisystem surveys (Table 4), zooplankton biomass in our study did not increase with reservoir productivity. This suggests that zooplankton biomass was not determined by abundance of edible algae, which did increase with reservoir productivity. Rather, zooplankton biomass in our study reservoirs may be better predicted from differences in planktivory across reservoirs, abiotic differences, such as flow rate and turbidity, or differences in the quality of algal resources.

\section{Foraging by larval gizzard shad linked to survival?}

Mismatches in scale likely caused our measures of larval foraging success and survival to be unrelated. For example, the positive relationship between foraging success and small copepod density that was evident when individual sampling dates were considered (Fig. 5) was less evident, particularly for large larvae, when mean May through June values were analyzed (Fig. 4). Because we treated all larvae within a reservoir as a single cohort with a single survival rate, our survival estimates were insensitive to variability in larval survival across time. As is the case for other fishes (Crecco and Savoy 1985, Mion et al. 1998), high survival over short time intervals (i.e., days) could produce the majority of gizzard shad survivors, particularly if hypereutrophic reservoirs support temporally variable densities of small zooplankton during periods critical to larvae. Under this scenario, foraging success over a short time interval by gizzard shad larvae would drive recruitment, but would preclude a strong relationship between mean foraging success and survival calculated over the broader time interval during which hatching occurs. 
TABLE 3. Predicting large larval survivors by combining larval gizzard shad hatch abundance with survival estimates from four Ohio reservoirs (reservoir identification numbers from Table 1), sampled during May through June 1993.

\begin{tabular}{cccc}
\hline \hline A) Recruitment factors & $\begin{array}{c}\text { Large larval } \\
\text { survivors }\end{array}$ & $\begin{array}{c}\text { Hatch } \\
\text { abundance }\end{array}$ & Survival \\
Reservoir & (observed no.) & (b) & 0.80 \\
1 & 62.0 & 77.2 & 0.78 \\
4 & 31.1 & 39.9 & 0.04 \\
8 & 0.1 & 2.3 & 0.11
\end{tabular}

B) Numbers of large larval survivors

\begin{tabular}{crrrr} 
& \multicolumn{4}{c}{ Reservoir } \\
\cline { 2 - 5 } Reservoir & \multicolumn{1}{c}{1} & \multicolumn{1}{c}{4} & 8 & 12 \\
\hline 1 & $\mathbf{6 2 . 0}$ & 31.9 & 1.8 & 2.1 \\
4 & 60.2 & $\mathbf{3 1 . 1}$ & 1.8 & 2.0 \\
8 & $\mathbf{3 . 1}$ & 1.6 & $\mathbf{0 . 1}$ & 0.1 \\
12 & 8.5 & 4.4 & 0.25 & $\mathbf{0 . 3}$ \\
\hline
\end{tabular}

Notes: (A) In each reservoir, observed number of large larval survivors (cumulative abundance per cubic meter during May through June) was divided by hatch abundance (cumulative abundance per cubic meter during May through June) to determine survival. Entries in (B) are products of survival and hatch corresponding to each pair of reservoirs. The numbers in bold along the diagonal correspond to observed values. Other entries are predicted numbers of large larval survivors for combinations of hatch abundance (columns) and survival probability (rows).

TABLE 4. Comparison of multisystem studies of zooplankton (ZP) size and biomass vs. lake and reservoir productivity.

\begin{tabular}{|c|c|c|c|c|c|}
\hline Reference & No. Systems & Geographic region & $\begin{array}{l}\text { Chlorophyll } \\
\text { range } \\
(\mu \mathrm{g} / \mathrm{L})\end{array}$ & $\begin{array}{l}\text { ZP size change } \\
\text { with increasing } \\
\text { productivity }\end{array}$ & $\begin{array}{l}\text { ZP biomass } \\
\text { change with } \\
\text { increasing } \\
\text { productivity }\end{array}$ \\
\hline Sprules (1980) & 36 lakes & Ontario & NA & $\begin{array}{l}\downarrow \text { with } \downarrow \text { depth and } \downarrow \\
\text { water clarity }\end{array}$ & NA \\
\hline Bays and Crisman (1983) & 39 reservoirs & Florida & $1-120$ & $\begin{array}{l}\uparrow \text { microzooplankton } \\
\text { (copepod nauplii, } \\
\text { rotifers, and ciliat- } \\
\text { ed protozoans) }\end{array}$ & increase \\
\hline Pace (1986) & 12 lakes & Quebec & $1.3-29$ & no change & increase \\
\hline Canfield (1988) & 45 reservoirs & $\begin{array}{l}\text { Iowa, Missouri, } \\
\text { Kansas, Oklahoma }\end{array}$ & 3-96 & no change & increase \\
\hline This study & 12 reservoirs & Ohio & $5-100$ & no change & no change \\
\hline
\end{tabular}

\section{Reservoir management}

Documented positive relationships between metrics of fish abundance (e.g., biomass or fishery yield) and system productivity (e.g., TP, total dissolved solids/ mean lake depth, or chlorophyll a) are well known in fisheries literature (Oglesby 1977, 1982, Jones and Hoyer 1982). Additionally, as productivity increases, so does the proportion of total fish biomass accounted for by "nonsport fish" (including gizzard shad; Ney 1996). This pattern underscores the need to understand how species such as gizzard shad are influenced by system productivity, and in turn, how they affect sport fishes and water clarity. Our study provides mechanistic insights, which we believe are critically important if managers are to develop tools for manipulating gizzard shad populations and hence their effects on sport fish recruitment and nutrient dynamics. 
By classifying reservoirs according to their level of gizzard shad recruitment, managers can develop short-term management strategies specific to the anticipated effects of gizzard shad on sport fish recruitment and water clarity. For example, the negative effects of gizzard shad depletion of zooplankton on age-0 bluegill and age-0 largemouth bass are most likely in hypereutrophic systems with very abundant gizzard shad (given that zooplankton production does not increase with TP). These negative effects are less likely in mesotrophic systems with relatively few gizzard shad. If eutrophic systems support moderate densities of slow-growing gizzard shad (which remain vulnerable to age-0 predators through midsummer), these reservoirs may be most likely to enjoy positive effects of gizzard shad on sport fish production (Dettmers and Stein 1996, DiCenzo et al. 1996, Stein et al. 1996, Bremigan and Stein 1999). Land-use practices could be altered to reduce reservoir productivity from hypereutrophic to eutrophic. By reducing TP loading to hypereutrophic systems, managers could shift reservoir environments from ones supporting gizzard shad recruitment and dominance to ones favoring sport fish recruitment (Stein et al. 1996).

Managers faced with managing multiple systems across many years should consider the relative importance of intersystem and interannual variability in prey fish recruitment. Patterns from previous field studies reveal that (1) as reservoir productivity increases, the probability that gizzard shad will dominate increases and (2) interannual variability in gizzard shad recruitment within mesotrophic and hypereutrophic systems is small relative to its variability between mesotrophic and hypereutrophic reservoirs (M. T. Bremigan and R. A. Stein, unpublished data). For example, gizzard shad first were stocked in reservoirs 1 and 4 in 1988. By 1990, peak densities of larval gizzard shad exceeded $20 / \mathrm{m}^{3}$ in these shallow, hypereutrophic systems, and reached 5-84 larvae $/ \mathrm{m}^{3}$ in subsequent years (peak densities $>20 / \mathrm{m}^{3}$ in 9 of 10 reservoir-years). In contrast, gizzard shad populations have occurred in this study's low productivity reservoirs typically for $>20 \mathrm{yr}$ (D. Bright, Ohio Division of Wildlife, Athens, Ohio, personal communication); yet, in these systems, they have remained at consistently low levels (peak densities in reservoirs 8 and 12 during 1992-1995 were $<3$ larvae/ $\mathrm{m}^{3}$ ).

Consideration of interannual and intersystem components of recruitment variability may be integrated with other efforts to develop a "multispecies" framework for understanding recruitment. For example, Miller et al. (1988) adopted a size-based perspective to conclude that size at hatch influences the relative importance of starvation and predation in determining recruitment across fish species. This perspective can be extended to suggest that freshwater fishes, which generally hatch at a large size relative to marine species, are more likely to have recruitment driven by predation, whereas marine species, with a generally small hatch size, are more likely to have recruitment driven by starvation (Houde 1994). We suggest building upon this approach by evaluating how life history characteristics influence the relative importance of intersystem and interannual variability in recruitment. For example, if weather at hatch is most important in driving recruitment (likely corresponding to a life history with small hatch size, no parental care, and fluctuating environmental conditions) then we would hypothesize that interannual variability in recruitment will be more extensive than intersystem variability. Generalizations gleaned from this work should contribute to our understanding of variability not only in fish populations but also in food web dynamics, because for fish species such as gizzard shad that function as strong interactors, factors underlying variability in their recruitment should also underlie variability in food web dynamics.

\section{ACKNOWLEDGMENTS}

We thank Sheri Strong Betz, Bobbie Jo Kennedy, and Kathy Massie for their tireless help in the lab and field. Nick Donovan and Jim Garvey generously contributed data to our survey. Dr. Mike Vanni kindly analyzed nutrient samples and offered insight into the role of gizzard shad in reservoir nutrient dynamics. Drs. Libby 
Marschall and Rusty Wright provided statistical guidance, and Dr. Pat Soranno provided valuable organizational suggestions on an earlier draft of this manuscript. This work was funded by the Department of Zoology at The Ohio State University, Electric Power Research Institute grant 91-07, National Science Foundation grants DEB 9107173 and DEB 9407859, and the Federal Aid in Sport Fish Restoration Project F-69-P, administered jointly by the U.S. Fish and Wildlife Service and the Ohio Division of Wildlife. We also thank the Ohio Cooperative Fish and Wildlife Research Unit for contributing facilities and personnel support to this effort.

\section{LiTERATURE CiTED}

Adams, S. M., and D. L. DeAngelis. 1987. Indirect effects of early bass-shad interactions on predator population structure and food web dynamics. Pages 103-117 in W. C . Kerfoot and A. Sih, editors. Predation: direct and indirect impacts on aquatic communities. University Press of New England, Hanover, New Hampshire, USA.

Arruda, J. A., G. R. Marzolf, and R. T. Faulk. 1983. The role of suspended sediments in the nutrition of zooplankton in turbid reservoirs. Ecology 64:1225-1235.

Bachman, R. W., B. L. Jones, D. D. Fox, M. Hoyer, L. A. Bull, and D. E. Canfield, Jr. 1996. Relations between trophic state indicators and fish in Florida (U.S.A.) lakes.

Canadian Journal of Fisheries and Aquatic Sciences 53: 842-855.

Bays, J. S., and T. L. Crisman. 1983. Zooplankton and trophic state relationships in Florida lakes. Canadian Journal of Fisheries and Aquatic Sciences 40:1813-1819.

Bean, D. L. 1980. Crustacean zooplankton production in Lake Erie, 1970. Thesis. The Ohio State University, Columbus, Ohio, USA.

Bodola, A. 1966. Life history of the gizzard shad, Dorosoma cepedianum (LeSueur) in western Lake Erie. U.S. Fish and Wildlife Service Fishery Bulletin 65:391-425.

Bottrell, H. H., A. Duncan, Z. M. Gliwicz, E. Grygierek, A. Herzig, A. Hillbricht-Ilkowska, H. Kurasawa, P. Larsson, and T. Weglenska. 1976. A review of some problems in zooplankton production studies. Norwegian Journal of Zoology 24:419-456.

Bremigan, M. T., and R. A. Stein. 1994. Gape-dependent larval foraging and zooplankton size: implications for fish recruitment across systems. Canadian Journal of Fisheries and Aquatic Sciences 51:913-922.

Bremigan, M. T., and R. A. Stein. 1997. Experimental assessment of the influence of zooplankton size and density on gizzard shad recruitment. Transactions of the American Fisheries Society 126:622-637.

Bremigan, M. T., and R. A. Stein. 1999. Larval gizzard shad success, juvenile effects, and reservoir productivity. Transactions of the American Fisheries Society 128:1106-1124.

Canfield, T. J. 1988. Relations among zooplankton abundance, biomass, community structure, and lake trophic state in selected midwestern waterbodies. Thesis. University of Missouri, Columbia, Missouri, USA.

Carlander, K. D. 1969. Handbook of freshwater fishery biology. Volume 1. The Iowa State University Press, Ames, Iowa, USA.

Crampton, W. G., T. M. Isenhart, and P. D. Mitchell. 1992. Nitrate and organic N analyses with second-derivative spectroscopy. Limnology and Oceanography 37:907-913.

Crecco, V. A., and T. F. Savoy. 1985. Effects of biotic and abiotic factors on growth and survival of young American shad (Alosa sapidissima) in the Connecticut River. Canadian Journal of Fisheries and Aquatic Sciences 42:1640- 1648 .

Culver, D. A., and W. R. DeMott. 1978. Production of zoo-plankton at nearshore stations in Lakes Ontario and Erie. Internationale Vereinigung fur theoretische und angewandte Limnologie Verhandlumgen 20:252-256.

DeMott, W. R. 1976. Zooplankton productivity at Locust Point, an inshore area in western Lake Erie. Thesis. The Ohio State University, Columbus, Ohio, USA.

Dettmers, J. M., and R. A. Stein. 1992. Food consumption by larval gizzard shad: zooplankton effects and its implications for reservoir communities. Transactions of the American Fisheries Society 121:494-507.

Dettmers, J. M., and R. A. Stein. 1996. Quantifying linkages among gizzard shad, zooplankton, and phytoplankton in reservoirs. Transactions of the American Fisheries Society 125:27-41.

DeVries, D. R., and R. A. Stein. 1990. Manipulating shad to enhance sport fisheries in North America: an assessment. North American Journal of Fisheries Management 10:209- 223.

DeVries, D. R., and R. A. Stein. 1991. Comparison of three zooplankton samplers: a taxon-specific assessment. Journal of Plankton Research 13:53-59.

DeVries, D. R., and R. A. Stein. 1992. Complex interactions between fish and zooplankton: quantifying the role of an open-water planktivore. Canadian Journal of Fisheries and Aquatic Sciences 49:1216-1227.

DeVries, D. R., R. A. Stein, J. G. Miner, and G. G. Mittelbach. 1991. Stocking threadfin shad: consequences for young-of-year fishes. Transactions of the American Fisheries Society 120:368-381. 
DiCenzo, V. J., M. J. Maceina, and M. R. Stimpert. 1996. Relations between reservoir trophic state and gizzard shad population characteristics in Alabama reservoirs. North American Journal of Fisheries Management 16:888-895.

Drenner, R. W., S. T. Threlkeld, and M. D. McCracken. 1986. Experimental analysis of the direct and indirect effects of an omnivorous filter-feeding clupeid on plankton community structure. Canadian Journal of Fisheries and Aquatic Sciences 43:1935-1945.

Dumont, H. J., I. Van de Velde, and S. Dumont. 1975. The dry weight estimate of biomass in a selection of Cladocera, Copepoda, and Rotifera from the plankton, periphyton and benthos of continental waters. Oecologia 19:75-97.

Garvey, J. E., N. A. Dingledine, N. S. Donovan, and R. A. Stein. 1998. Exploring spatial and temporal variation within reservoir food webs: predictions for fish assemblages. Ecological Applications 8:104-120.

Garvey, J. E., and R. A. Stein. 1998. Linking bluegill and gizzard shad prey assemblages to growth of age-0 largemouth bass in reservoirs. Transactions of the American Fisheries Society 127:70-83.

Gliwicz, Z. M. 1975. Effect of zooplankton grazing on photosynthetic activity and composition of phytoplankton. Internationale Vereinigung fur theoretische und angewandte Limnologie Verhandlumgen 19:1490-1497.

Hart, P. J. B., and B. Connellan. 1984. Cost of prey capture, growth rate and ration size in pike, Esox lucius L., as functions of prey weight. Journal of Fish Biology 25:279-292.

Houde, E. D. 1994. Differences between marine and freshwater fish larvae: implication for recruitment. ICES Journal of Marine Science 51:91-97.

Jones, M. L., J. F. Koonce, and R. O'Gorman. 1993. Sustainability of hatchery dependent salmonine fisheries in Lake Ontario: the conflict between predator demand and prey supply. Transactions of the American Fisheries Society 122:1002-1018.

Jones, R. J., and M. V. Hoyer. 1982. Sportfish harvest predicted by summer chlorophyll-a concentration in mid western lakes and reservoirs. Transactions of the American Fisheries Society 111:176-179.

Kerfoot, W. C., and A. Sih. 1987. Predation: direct and indirect impacts on aquatic communities. University Press of New England, Hanover, New Hampshire, USA.

Lind, O. T. 1985. Handbook of common methods in limnology. Kendall/Hunt, Dubuque, Iowa, USA.

Ludsin, S. A., and D. R. DeVries. 1997. First-year recruitment of largemouth bass: the interdependency of early life stages. Ecological Applications 7:1024-1038.

Miller, T. J., L. B. Crowder, J. A. Rice, and E. A. Marschall. 1988. Larval size and recruitment mechanisms in fishes: toward a conceptual framework. Canadian Journal of Fisheries and Aquatic Sciences 45:1657-1670.

Mills, E. L., and J. L. Forney. 1988. Trophic dynamics and development of freshwater pelagic food webs. Pages 1130 in S. R. Carpenter, editor. Complex interactions in lake communities. Springer-Verlag, New York, New York, USA.

Mills, E. L., D. M. Green, and A. Schiavone, Jr. 1987. Use of zooplankton size to assess the community structure of fish populations in freshwater lakes. North American Journal of Fisheries Management 7:369-378.

Mion, J. B., R. A. Stein, and E. A. Marschall. 1998. River discharge drives survival of larval walleye. Ecological Applications 8:88-103.

Miranda, S., G. Jons, and H. Gu. 1994. Factors limiting recruitment of age-0 gizzard shad in Bay Springs Reservoir. Final Report, Federal Aid in Sport fish Restoration, Project F98. Mississippi Department of Wildlife, Fisheries and Parks, Jackson, Mississippi, USA.

Mundahl, N. D., and T. E. Wissing. 1987. Nutritional importance of detritivory in the growth and condition of

gizzard shad in an Ohio reservoir. Environmental Biology of Fishes 20:129-142.

Ney, J. J. 1996. Oligotrophication and its discontents: effects of reduced nutrient loading on reservoir fisheries. Pages 285-295 in L. E. Miranda and D. R. DeVries, editors. Multidimensional approaches to reservoir fisheries management. American Fisheries Society Symposium 16.

Noble, R. L. 1981. Management of forage fishes in impoundments of the southern United States. Transactions of the American Fisheries Society 110:738-750.

Oglesby, R. T. 1977. Relationships of fish yield to lake phytoplankton standing crop, production, and morphoedaphic factors. Journal of the Fisheries Research Board of Canada 34:2271-2279.

Oglesby, R. T. 1982. The MEI symposium-overview and observations. Transactions of the American Fisheries Society 111:171-175.

Olson, M. H. 1996. Predator-prey interactions in size-structured fish communities: implications of prey growth. Oecologia 108:757-763.

Olson, M. H., G. G. Mittelbach, and C. W. Osenberg. 1995. Competition between predator and prey: resource-based mechanisms and implications for stage-structured dynamics. Ecology 76:1758-1771.

Pace, M. L. 1986. An empirical analysis of zooplankton community size structure across lake trophic gradients. Limnology and Oceanography 31:45-55. 
Paine, R. T. 1980. Food webs: linkage, interaction strength and community infrastructure. Ecology 49:667-685.

Parrish, D. L., and B. Vondracek. 1989. Population dynamics and ecology of Lake Erie gizzard shad. Ohio Department of Natural Resources, Federal Aid in Sport Fish Restoration, Annual Performance Report, Project F-61-R, Columbus, Ohio, USA.

Porter, K. G. 1977. The plant-animal interface in freshwater systems. American Scientist 65:159-170.

Soranno, P. A. 1990. Methods of the cascading trophic interactions project. University of Wisconsin, Madison, Wisconsin, USA.

Sprules, W. G. 1980. Zoogeographic patterns in size structure of zooplankton communities, with possible applications to lake ecosystem modeling and management. Pages 642-656 in W. C. Kerfoot, editor. Evolution and ecology of zooplankton communities. University Press of New England, Hanover, New Hampshire, USA.

Stein, R. A., M. T. Bremigan, and J. M. Dettmers. 1996. Understanding reservoir systems with experimental tests of ecological theory: a prescription for management. Pages 12-22 in L. E. Miranda and D. R. DeVries, editors. Multidimensional approaches to reservoir fisheries management. American Fisheries Society Symposium 16.

Stein, R. A., D. R. DeVries, and J. M. Dettmers. 1995. Food-web regulation by a planktivore: exploring the generality of the trophic cascade hypothesis. Canadian Journal of Fisheries and Aquatic Sciences 52:25182526.

Storck, T. W. 1986. Importance of gizzard shad in the diet of largemouth bass in Lake Shelbyville, Illinois. Transactions of the American Fisheries Society 115:21-27.

Swingle, H. S. 1949. Experiments with combinations of largemouth bass, bluegill, and minnows in ponds. Transactions of the American Fisheries Society 76:46-62.

Wahl, D. H., and R. A. Stein. 1988. Selective predation by three esocids: the role of prey behavior and morphology. Transactions of the American Fisheries Society 117:142-151.

Werner, E. E., and J. F. Gilliam. 1984. The ontogenetic niche and species interactions in size-structured populations. Annual Review of Ecology and Systematics 15:393-426. 